\title{
RING ANNULOPLASTY PREVENTS DELAYED LEAFLET COAPTATION AND MITRAL REGURGITATION DURING ACUTE LEFT VENTRICULAR ISCHEMIA
}

Tomasz Timek, MD ${ }^{\mathrm{a}}$

Julie R. Glasson, MD ${ }^{\mathrm{a}}$

Paul Dagum, MD, $\mathrm{PhD}^{\mathrm{a}}$

G. Randall Green, MD

J. Francisco Nistal, MD, PhD

Masashi Komeda, MD, $\mathrm{PhD}^{\mathrm{a}}$

George T. Daughters, $\mathrm{MS}^{\mathrm{a}, \mathrm{d}}$

Ann F. Bolger, MD

Linda E. Foppiano, $\mathrm{MD}^{\mathrm{b}}$

Neil B. Ingels, Jr, $\mathrm{PhD}^{\mathrm{a}, \mathrm{d}}$

D. Craig Miller, MD
Objective: Incomplete mitral leaflet coaptation during acute left ventricular ischemia is associated with end-diastolic mitral annular dilatation and ischemic mitral regurgitation. Annular rings were implanted in sheep to investigate whether annular reduction alone is sufficient to prevent mitral regurgitation during acute posterolateral left ventricular ischemia.

Methods: Radiopaque markers were inserted around the mitral anulus, on papillary muscle tips, and on the central meridian of both mitral leaflets in three groups of sheep: control $(n=5)$, Physio ring $(n=5)$ (Baxter Cardiovascular Div, Santa Ana, Calif), and Duran ring $(n=6)$ (Medtronic Heart Valve Div, Minneapolis, Minn). After $8 \pm 1$ days, animals were studied with biplane videofluoroscopy before and during left ventricular ischemia. Annular area was calculated from 3-dimensional marker coordinates and coaptation defined as minimal distance between leaflet edge markers.

Results: Before ischemia, leaflet coaptation occurred just after end-diastole in all groups (control $17 \pm 41$, Duran $33 \pm 30$, Physio $33 \pm 24$ ms, mean \pm $\mathrm{SD}, P>.2$ by analysis of variance). During ischemia, regurgitation was detected in all control animals, and leaflet coaptation was delayed to $88 \pm 8$ ms after end-diastole ( $P=.02$ vs preischemia). This was associated with increased end-diastolic annular area $\left(8.0 \pm 0.9\right.$ vs $\left.6.7 \pm 0.6 \mathrm{~cm}^{2}, P=.004\right)$ and septal-lateral annular diameter $(2.9 \pm 0.1$ vs $2.5 \pm 0.1 \mathrm{~cm}, P=.02)$. Mitral regurgitation did not develop in Duran or Physio sheep, time to coaptation was unchanged (Duran $25 \pm 25 \mathrm{~ms}$, Physio $30 \pm 48 \mathrm{~ms}$ [both $P>.2$ vs preischemia]), and annular area remained fixed.

Conclusion: Mitral annular area reduction and fixation with an annuloplasty ring eliminated delayed leaflet coaptation and prevented mitral regurgitation during acute left ventricular ischemia after ring implantation. ( $\mathrm{J}$ Thorac Cardiovasc Surg 2000;119:774-83) schemic mitral regurgitation (MR) is a common clinical problem with a wide spectrum of presentations. ${ }^{1}$ It is associated with a high operative mortality and poor longterm outcome due to left ventricular (LV) systolic dys-

From the Department of Cardiovascular and Thoracic Surgery, ${ }^{\text {a The }}$ Division of Cardiovascular Medicine, and the Department of

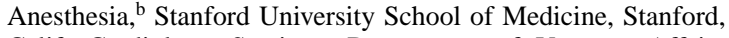
Calif; Cardiology Section, ${ }^{c}$ Department of Veterans Affairs Medical Center, Palo Alto, Calif; and the Department of Cardiovascular Physiology and Biophysics, ${ }^{\mathrm{d}}$ Research Institute of the Palo Alto Medical Foundation, Palo Alto, Calif.

Supported by grants HL-29589 and HL-48837 from the National Heart, Lung, and Blood Institute. Drs Timek, Glasson, Green, Dagum, and Komeda are Carl and Leah McConnell Cardiovascular Surgical Research Fellows. Drs Timek and Glasson are also recipients of fellowship awards from The Thoracic Surgery Foundation for Research and Education. Drs Green and Dagum were also supported by National Heart, Lung, function, which is inherent to its pathophysiology. ${ }^{2-5}$ Valve repair rather than replacement has been purported to be associated with superior surgical outcomes in this patient population. ${ }^{6}$ Although several techniques of

and Blood Institute Individual Research Service Awards HL09569 and HL-10000, respectively.

Presented in part at the Seventy-first American Heart Association Annual Scientific Sessions, Dallas, Tex, November 1998.

Received for publication Aug 26, 1999; revisions requested Oct 11, 1999; revisions received Nov 12, 1999; accepted for publication Nov 14, 1999.

Address for reprints: D. Craig Miller, MD, Department of Cardiovascular and Thoracic Surgery, Falk Cardiovascular Research Center, Stanford University School of Medicine, Stanford, CA 94305-5247 (E-mail: dcm@leland.stanford.edu).

12/1/104471

doi:10.1067/mtc.2000.104471 
mitral valve reconstruction with an annuloplasty ring have been developed over the years for prolapse, ${ }^{7}$ in patients with MR resulting from coronary artery disease the leaflets and subvalvular apparatus usually are completely normal, annular dilatation may be present, yet leaflet motion typically is either normal (Carpentier type I) or restricted during systole (Carpentier type IIIb). ${ }^{8}$ The combination of these derangements and the underlying LV dysfunction results in incomplete mitral leaflet coaptation, which can be seen with either Carpentier type I or type IIIb leaflet motion. Mitral annuloplasty alone (usually with a small ring) is claimed to be efficacious in treating ischemic MR. ${ }^{6,89}$ It is believed that annular remodeling allows better approximation of the leaflet edges, which facilitates leaflet coaptation and prevents MR. The exact mechanism of how annuloplasty reduces MR, however, is unknown.

Recent experimental studies have revealed that acute posterolateral LV ischemia in sheep is associated with annular dilatation and incomplete mitral leaflet coaptation due to early systolic "loitering" (or delayed closure) of both leaflets, which can cause ischemic MR. ${ }^{10}$ Increased end-diastolic mitral septal-lateral (S-L) annular diameter during ischemia may play a role in the genesis of incomplete mitral leaflet coaptation and ischemic MR in this model. Therefore prevention of annular dilatation and reduction of the S-L annular dimension by ring annuloplasty may abolish ischemic MR in this acute model. However, it should also be considered that ring annuloplasty affects the geometry and function of the mitral subvalvular complex, which could theoretically either exacerbate or ameliorate incomplete mitral leaflet coaptation. In this current study, we used the myocardial marker technology ${ }^{11}$ to investigate the effects of semirigid or flexible ring annuloplasty on the 3-D geometry and motion of the mitral valve anulus and leaflets in this experimental ovine model of acute ischemic MR.

\section{Methods}

Surgical preparation. Sixteen adult castrated male sheep were randomized into three groups: Group $\mathrm{C}(\mathrm{n}=5)$ underwent placement of myocardial markers only to serve as a control group; the results in these animals have been previously reported. ${ }^{10}$ Groups $\mathrm{D}(\mathrm{n}=6)$ and $\mathrm{P}(\mathrm{n}=5)$ also underwent annuloplasty with either a Duran ring (Medtronic Heart Valve Div, Minneapolis, Minn) or a Carpentier-Edwards Physio ring (Baxter Cardiovascular Div, Santa Ana, Calif), respectively. The surgical preparation has been described in detail previously $^{12}$ and will be summarized only briefly. Eight subepicardial tantalum markers (inner diameter $0.8 \mathrm{~mm}$, outer diameter $1.3 \mathrm{~mm}$, length $1.5-3.0 \mathrm{~mm}$ ) were inserted along 4 equally spaced LV longitudinal meridians. Eight

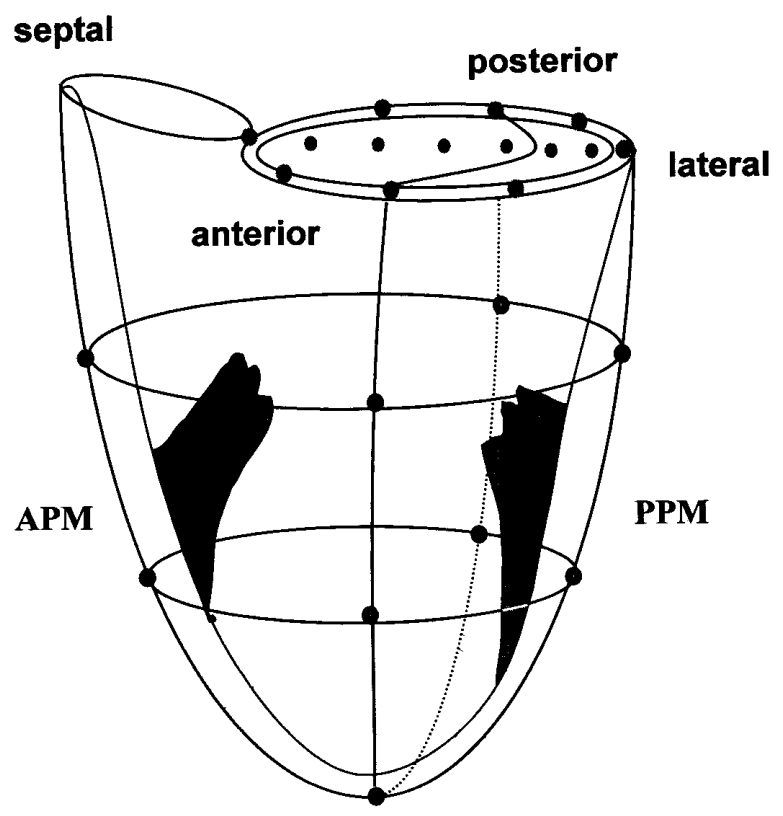

Fig 1. Array of myocardial and valvular markers used in this experimental study. APM, Anterior papillary muscle; $P P M$, posterior papillary muscle.

miniature tantalum radiopaque markers were sutured equidistantly (approximately every $45^{\circ}$ ) around the circumference of the mitral anulus ( 1 near each commissure and 3 along the anterior and posterior anuli). Additional miniature gold markers were sutured along the central meridian of the anterior (3 markers) and posterior ( 2 markers) leaflets with the edge markers being placed on the ventricular surface. One marker was placed on each papillary muscle tip. The complete marker array is shown in Fig 1. In the Duran and Physio groups, ring sizes were chosen on the basis of the area of the anterior leaflet and the intertrigonal distance (the standard clinical method); these rings were not undersized. The Duran animals received five $31-\mathrm{mm}$ rings and one $29-\mathrm{mm}$ ring, whereas a 28-mm ring was implanted in all animals of the Physio group.

Experimental protocol. After $8 \pm 4$ days (mean $\pm 1 \mathrm{SD})$, each animal was studied in the experimental cardiac catheterization laboratory, sedated (ketamine 1 to $4 \mathrm{mg} / \mathrm{kg}$ per hour intravenous infusion and diazepam $5 \mathrm{mg}$ intravenous bolus as needed), intubated, and the lungs mechanically ventilated. Excessive tachycardia was prevented by administration of UL-FS49 (8 mg intravenously, Boehringer-Ingelheim, Ridgefield, Conn), a highly specific chronotropic agent that does not change the QT interval, inotropic state, or systolic or diastolic blood pressure. ${ }^{13}$ Esmolol (20 to $50 \mu \mathrm{g} \cdot \mathrm{kg}^{-1}$. $\left.\mathrm{min}^{-1}\right)$ and atropine sulfate $\left(0.01 \mathrm{mg} \cdot \mathrm{kg}^{-1} \cdot \mathrm{min}^{-1}\right)$ intravenous infusions were used to minimize reflex sympathetic and parasympathetic responses. Balloon occlusion of the left circumflex coronary artery (distal to the first obtuse marginal artery) to produce LV posterolateral ischemia was carried out as previously reported. ${ }^{10}$ Simultaneous biplane videofluoroscopy and hemodynamic data recordings were obtained 
Table I. Animal weights, operative times, and duration of coronary occlusion

\begin{tabular}{lcccc}
\hline & Control & Duran & Physio & ANOVA \\
\hline Weight (kg) & $60 \pm 11$ & $70 \pm 7$ & $71 \pm 11$ & $>.2$ \\
Cx balloon occlusion & $3.3 \pm 3.8$ & $2.5 \pm 1.5$ & $2.7 \pm 1.8$ & $>.2$ \\
$\quad$ time (min) & & & & \\
CPB time (min) & $106 \pm 9$ & $132 \pm 12$ & $134 \pm 15$ & .01 \\
Crossclamp time (min) & $58 \pm 5$ & $90 \pm 5$ & $90 \pm 9$ & .001
\end{tabular}

$C x$, Left circumflex coronary artery; $C P B$, cardiopulmonary bypass.

during steady-state conditions and over a range of LV filling volumes during abrupt preload reduction achieved with vena caval occluders. Data recordings were acquired initially before induction of ischemia; after 3 to 5 minutes of stabilization, mid circumflex occlusion was created that resulted in posterolateral LV ischemia and $\mathrm{MR}$, and data recordings were repeated. MR was verified by an experienced echocardiographer using transthoracic Doppler echocardiography and graded on the basis of regurgitant jet width and extent relative to left atrial area: none, 0 ; mild, +1 ; moderate, +2 ; moderate to severe, +3 ; and severe, +4 . Echocardiography was performed at the end of the circumflex artery occlusion (Table I) with the balloon still inflated.

All animals received humane care in compliance with the "Principles of Laboratory Animal Care" formulated by the National Society for Medical Research and "Guide for the Care and Use of Laboratory Animals" prepared by the Institute of Laboratory Animal Resources, National Research Council, and published by the National Academy Press, revised 1996. This study was approved by the Stanford Medical Center Laboratory Research Animal Review committee and conducted according to Stanford University policy.

Data acquisition. Images were acquired with the animal in the right lateral decubitus position with a Philips Optimus 2000 biplane lateral ARC 2/Poly DIAGNOST C2 system (Phillips Medical Systems, North America Company, Pleasanton, Calif) with the image intensifier in the 9-inch fluoroscopic mode. Data from two radiographic views were digitized and merged to yield 3-dimensional coordinates for each of the radiopaque markers every 16.7 seconds with custom-designed software. ${ }^{14}$ Descending thoracic aortic pressure, LV pressure, and electrocardiographic voltage signals were digitized and recorded simultaneously during data acquisition.

\section{Data analysis}

Hemodynamic and cardiac cycle timing markers. Two consecutive steady state beats during control and acute ischemic conditions were averaged and defined as "control" and "ischemic" data for each animal, respectively. For each cardiac cycle, end-systole was defined as the videofluoroscopic frame containing peak negative LV rate of pressure rise $(-\mathrm{dP} / \mathrm{dt})$, and end-diastole was defined as the videofluoroscopic frame containing the peak of the electrocardiographic $\mathrm{R}$ wave. Instantaneous $\mathrm{LV}$ volume was calculated from the epicardial LV markers with a space-filling multiple tetrahe- dral volume method every 16.7 ms. ${ }^{15}$ Although LV wall mass is included in this calculation of LV volume, it accurately reflects relative changes in LV chamber size ${ }^{16}$ but does overestimate absolute LV chamber volume. Stroke volume (SV) was calculated as the difference between end-diastolic (EDV) and end-systolic (ESV) volume (SV = EDV - ESV), and ejection fraction (EF) was calculated as (EDV - ESV)/EDV. These computed EFs were underestimates, as the calculated epicardial $\mathrm{LV}$ volumes included myocardial LV wall volume.

$L V$ function. External LV pressure-volume stroke work (SW) was calculated as the integral of LV pressure $(\mathrm{P})$ multiplied by volume $(\mathrm{V})$ over a cardiac cycle for several beats at baseline and during caval occlusion as follows:

$$
\mathrm{SW}=\int \mathrm{P} \cdot \mathrm{dV}
$$

Preload recruitable stroke work was computed by linear regression of SW on EDV as follows:

$$
\mathrm{SW}=\mathrm{MW}(\mathrm{EDV}-\mathrm{VW})
$$

where MW and VW are the slope and volume axis intercepts, respectively.

Mitral leaflet and annular dynamics. Mitral leaflet coaptation was defined as the minimum distance measured in 3dimensional space between the 2 leaflet edge markers after this value reached a plateau. Mitral annular area was calculated by determining the centroid of the 8 annular markers, subsequently dividing the anulus into 8 triangular "piepieces" and summing their 8 individual areas. The S-L diameter was obtained by calculating the linear distance in 3dimensional space between the 2 markers placed in the middle of the anterior ("saddlehorn") and posterior anulus, respectively. In similar fashion, the commissure-commissure (C-C) diameter was calculated as the 3-dimensional distance between the 2 commissural markers. To describe the 3dimensional geometry of the mitral leaflets and papillary tips, we transformed the marker coordinates from their original laboratory reference frame to a Cartesian coordinate system having its origin at the midpoint of the line defining the S-L diameter, with the Y-axis directed from this origin to the LV apex marker. In this coordinate system, the positive Y-axis is directed away from the annular plane toward the LV apex, and the $\mathrm{X}$-axis is positive toward the lateral LV wall.

Statistical analysis. All data are reported as mean plus or minus 1 standard deviation $( \pm 1 \mathrm{SD})$ unless otherwise stated. Hemodynamic and marker-derived data from two steady state beats were time aligned at end-diastole. Data were analyzed from two consecutive beats, except in one control animal in which only one beat was available. The mean and SD for each variable were computed for 9,14 , and 12 beats in the control, Duran, and Physio groups, respectively. For calculations of preload recruitable stroke work in the control group, 8 beats were available since acquisition of caval occlusion volumes was incomplete in 1 animal. Marker data were analyzed over 15 frames before and after end-diastole, thus allowing evaluation over a time period of $500 \mathrm{~ms}$. Data were compared within each group by means of the Student $t$ test for paired observations, and intergroup comparisons were made by means of analysis of variance (ANOVA) with post 
Table II. Hemodynamic variables in the three groups before and after ischemia

\begin{tabular}{|c|c|c|c|c|c|c|c|c|}
\hline & \multicolumn{3}{|c|}{ Preischemia } & \multirow[b]{2}{*}{ ANOVA } & \multicolumn{3}{|c|}{ Ischemia } & \multirow[b]{2}{*}{ ANOVA } \\
\hline & Control & Duran & Physio & & Control & Duran & Physio & \\
\hline $\operatorname{HR}\left(\min ^{-1}\right)$ & $110 \pm 10$ & $113 \pm 12$ & $111 \pm 10$ & $>.2$ & $93 \pm 26$ & $102 \pm 26$ & $93 \pm 33$ & $>.2$ \\
\hline $\mathrm{dP} / \mathrm{dt}_{\max }(\mathrm{mm} \mathrm{Hg} / \mathrm{s})$ & $1985 \pm 418$ & $1537 \pm 338$ & $1762 \pm 372$ & .19 & $1386 \pm 449^{\dagger}$ & $1087 \pm 393$ & $1279 \pm 201^{\dagger}$ & $>.2$ \\
\hline $\mathrm{EDV}(\mathrm{mL})$ & $140 \pm 32$ & $197 \pm 43$ & $177 \pm 47$ & .11 & $145 \pm 34$ & $196 \pm 40$ & $179 \pm 46$ & .15 \\
\hline ESV (mL) & $112 \pm 22$ & $159 \pm 27$ & $141 \pm 44$ & .08 & $123 \pm 22^{\ddagger}$ & $168 \pm 40$ & $147 \pm 44$ & .16 \\
\hline $\mathrm{SV}(\mathrm{mL})$ & $29.5 \pm 11$ & $38.0 \pm 18.1$ & $36.3 \pm 5.9$ & $>.2$ & $22.9 \pm 13.5^{*}$ & $28.5 \pm 4.9$ & $31.6 \pm 9.7$ & $>.2$ \\
\hline $\mathrm{EF}$ & $0.20 \pm 0.04$ & $0.19 \pm 0.05$ & $0.21 \pm 0.04$ & $>.2$ & $0.15 \pm 0.06^{*}$ & $0.15 \pm 0.04$ & $0.18 \pm 0.07$ & .07 \\
\hline LVEDP (mm Hg) & $17.9 \pm 2.6$ & $26.1 \pm 4.7$ & $19.4 \pm 6.9$ & .06 & $21.3 \pm 6.5$ & $22.6 \pm 8.0$ & $22.8 \pm 5.1$ & $>.2$ \\
\hline LVESP (mm Hg) & $97 \pm 23$ & $101 \pm 13$ & $101 \pm 14$ & $>.2$ & $64 \pm 16^{*}$ & $75 \pm 26^{*}$ & $53 \pm 11^{\ddagger}$ & $>.2$ \\
\hline $\mathrm{LVP}_{\max }(\mathrm{mm} \mathrm{Hg})$ & $132 \pm 18$ & $120 \pm 15$ & $121 \pm 18$ & $>.2$ & $86 \pm 9^{\dagger}$ & $90 \pm 26^{*}$ & $85 \pm 12^{\dagger}$ & $>.2$ \\
\hline PRSW (mm Hg/mL) & $66.5 \pm 10.6$ & $55.1 \pm 13.4$ & $69.3 \pm 18.7$ & $>.2$ & $45.9 \pm 9.6^{*}$ & $43.3 \pm 14.8$ & $40.7 \pm 15.4^{*}$ & $>.2$ \\
\hline
\end{tabular}

$H R$, Heart rate; $d P / d t_{\max }$, maximum positive rate of change of LV pressure; $E D V, \mathrm{LV}$ end-diastolic volume; $E S V$, LV end-systolic volume; $S V$, LV stroke volume; $E F$, LV ejection fraction (nota bene: by epicardial markers, not LV chamber EF); LVEDP, LV end-diastolic pressure; $L V E S P$, LV end-systolic pressure; $L V P$ max maximum systolic LV pressure; PRSW, preload recruitable stroke work.

${ }^{*} P<.05$.

${ }^{\dagger} P<.01$.

$\stackrel{+}{+}<<.001$.

hoc Bonferroni correction. Because of large variances and the possibility of nonnormally distributed variance, nonparametric statistical analysis with the Kruskal-Wallis test was also performed for certain variables.

\section{Results}

Marker position was confirmed in all animals at postmortem examination; LV epicardial markers were within $1 \mathrm{~mm}$ of the epicardial surface, and all mitral anulus, papillary tip, and leaflet markers were present. No ring dehiscence or vegetations were noted in the ring groups. Animal weights, operative times, and duration of coronary occlusion are summarized in Table I. No statistically significant difference in weight was present between the groups. Cardiopulmonary bypass and crossclamp times were significantly longer in the Duran and Physio groups. Duration of left circumflex balloon catheter occlusion was similar in the three groups.

Hemodynamics. Hemodynamic variables in the three groups before and after ischemia are presented in Table II. There was no significant difference between the groups with respect to heart rate, $\mathrm{dP} / \mathrm{dt}$, end-diastolic volume, end-systolic volume, ejection fraction, LV end-diastolic pressure, and LV end-systolic pressure at baseline or after acute posterolateral ischemia. (Note that the low computed ejection fractions are not indicative of profoundly depressed LV systolic function. These low numbers result from using the LV epicardial markers to calculate end-diastolic and end-systolic volumes. Therefore, LV wall thickening is not detected during systole and chamber end-diastolic volume is markedly overestimated, since LV myocardial mass is included. These ejection fractions in the low 20s correspond to angiographic LV chamber ejection fractions of around 0.50.) Although no change in enddiastolic volume was seen with ischemia in all groups, end-systolic volume increased in the control group. Comparable degrees of ischemia were induced in the three groups as evidenced by a similar decrease in $\mathrm{LV}$ $\mathrm{dP} / \mathrm{dt}$ (control, $-31 \% \pm 12 \%$; Duran, $-28 \% \pm 24 \%$; Physio, $-27 \% \pm 7 \%$ ), and maximum LV pressure (control, $-34 \% \pm 6 \%$; Duran, $-26 \% \pm 17 \%$; Physio, $-30 \%$ $\pm 6 \%$ ). Preload recruitable stroke work, a load-independent measure of contractility, revealed a somewhat lesser degree of change during ischemia in the Duran group (control, $-31 \% \pm 9 \%$; Duran, $-17 \% \pm 30 \%$; Physio, $-38 \% \pm 24 \%$ ), but caution is necessary in interpreting these changes in the presence of LV regional systolic wall motion abnormalities accompanying the ischemic insult.

Mitral valve competence. No MR was detected by transthoracic Doppler echocardiography at baseline in the control group. After induction of ischemia, moderate to severe MR developed in 2 animals, and $3 \mathrm{had}$ mild to moderate MR. In the ring groups, trace MR was noted in 1 Duran and 1 Physio animal before ischemia, and the MR did not change with circumflex occlusion. The remaining sheep did not have MR at baseline or during ischemia.

Mitral leaflet coaptation and shape. Fig 2 illustrates the changes in mitral leaflet edge separation, annular area, and LV pressure at baseline and during acute ischemia in the three groups. Numerical data and statistical analysis are summarized in Table III. Valve closure times, as measured from end-diastole, were not 

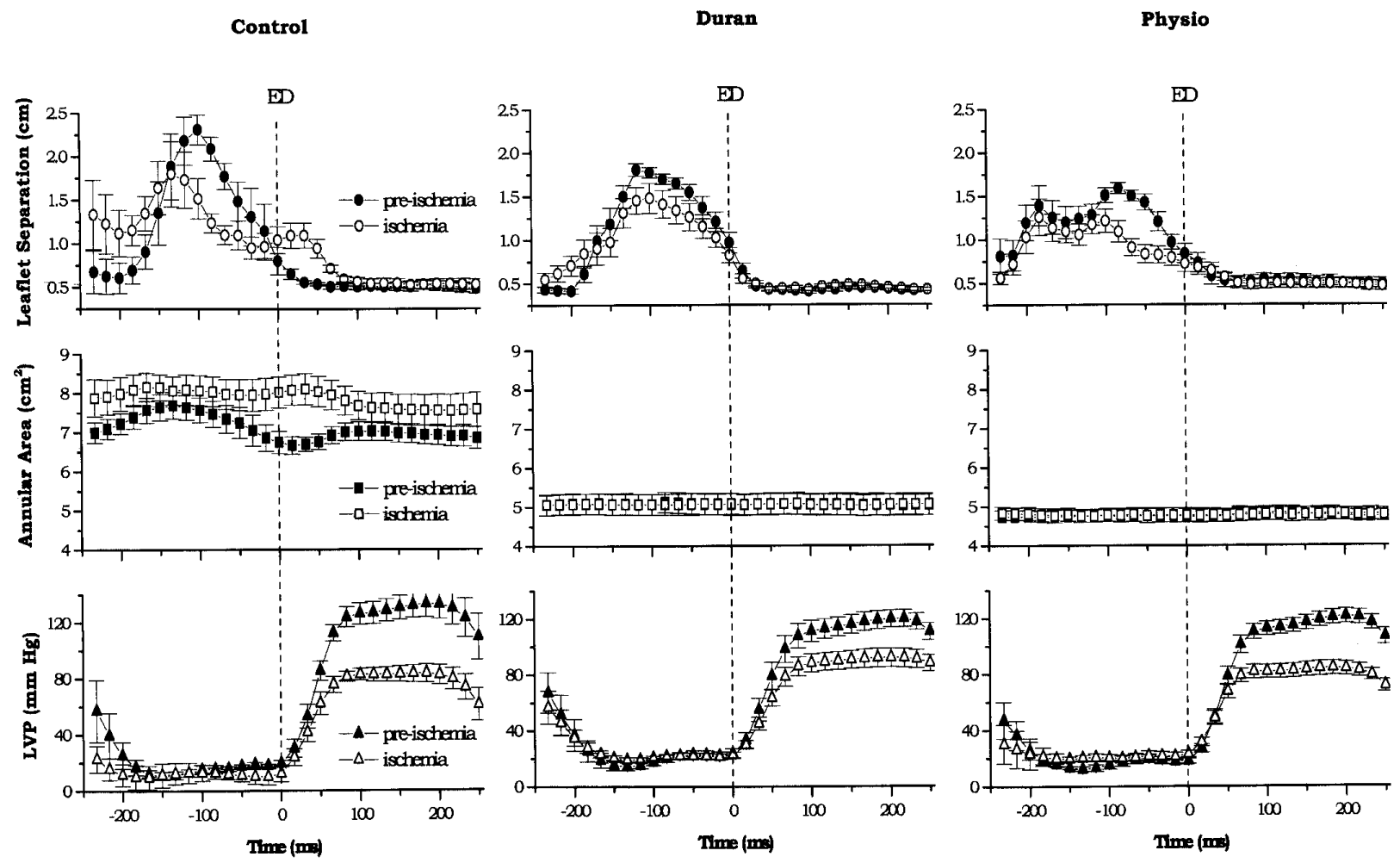

Fig 2. Leaflet edge separation (cm), annular area $\left(\mathrm{cm}^{2}\right)$, and LV pressure $(L V P)(\mathrm{mm} \mathrm{Hg})$ before (closed symbols) and during (open symbols) acute posterolateral LV ischemia. A 500-ms time frame centered at end-diastole (dashed line) is illustrated for all three groups. Error bars indicate 1 standard error of the mean.

Table III. Numerical data and statistical analysis

\begin{tabular}{|c|c|c|c|c|c|c|c|c|}
\hline & \multicolumn{3}{|c|}{ Preischemia } & \multirow[b]{2}{*}{ ANOVA } & \multicolumn{3}{|c|}{ Ischemia } & \multirow[b]{2}{*}{ ANOVA } \\
\hline & Control & Duran & Physio & & Control & Duran & Physio & \\
\hline Time, ED to closure (ms) & $16.7 \pm 40.9$ & $33.4 \pm 29.9$ & $33.4 \pm 23.6$ & $>.2$ & $87.7 \pm 8.4^{*}$ & $25.1 \pm 25.3$ & $30.1 \pm 47.8$ & .007 \\
\hline Annular area at ED $\left(\mathrm{cm}^{2}\right)$ & $6.74 \pm 0.64$ & $5.06 \pm 0.68$ & $4.75 \pm 0.45$ & .001 & $8.02 \pm 0.89^{\dagger}$ & $5.07 \pm 0.70$ & $4.78 \pm 0.43$ & .001 \\
\hline S-L distance at ED $(\mathrm{cm})$ & $2.52 \pm 0.10$ & $2.23 \pm 0.23$ & $2.15 \pm 0.12$ & .01 & $2.85 \pm 0.14^{*}$ & $2.27 \pm 0.22^{*}$ & $2.15 \pm 0.13$ & .001 \\
\hline $\mathrm{C}-\mathrm{C}$ distance at ED $(\mathrm{cm})$ & $3.54 \pm 0.22$ & $2.86 \pm 0.14$ & $2.91 \pm 0.34$ & .001 & $3.58 \pm 0.22$ & $2.83 \pm 0.15$ & $2.90 \pm 0.36$ & .001 \\
\hline S-L/C-C at ED & $0.71 \pm 0.05$ & $0.78 \pm 0.06$ & $0.75 \pm 0.09$ & $>.2$ & $0.80 \pm 0.08$ & $0.80 \pm 0.05$ & $0.75 \pm 0.11$ & $>.2$ \\
\hline MR & 0 & $+0.1 \pm 0.2$ & $+0.1 \pm 0.2$ & & $+2.1 \pm 0.8$ & $+0.1 \pm 0.2$ & $+0.1 \pm 0.2$ & \\
\hline
\end{tabular}

$E D$, End-diastole; $S$ - $L$, septal-lateral dimension of the mitral anulus (from the middle of the anterior anulus [saddlehorn] to the middle of the posterior anulus); $C$ - $C$, commissure-commissure dimension of the mitral anulus.

${ }^{*} P<.05$.

${ }^{\dagger} P<.01$ by paired $t$ test.

significantly different at baseline in the three groups $(P$ $>$.2, ANOVA). During ischemia, however, valve closure in the control group was significantly delayed versus baseline ( $16.7 \pm 40.9 \mathrm{~ms}$ vs $87.7 \pm 8.4 \mathrm{~ms}, P=.02$ ) and also in comparison with the ischemic valve closure times in the ring groups ( $P=.007$, ANOVA). The times of valve closure in the Duran and Physio groups during ischemia did not differ significantly from preischemic conditions (Duran $33.4 \pm 29.9 \mathrm{~ms}$ vs $25.1 \pm 25.3 \mathrm{~ms}, P$ > .2; Physio $33.4 \pm 23.6 \mathrm{~ms}$ vs $30.1 \pm 47.8 \mathrm{~ms}, P>.2$ ).
Due to large variance in the time to valve closure among the three groups, nonparametric statistical analysis (Kruskal-Wallis test) revealed no significant difference in the time of valve closure among the three groups at baseline $(P>.2)$ and confirmed the significance of the delayed valve closure times in the control group versus the ring groups during posterolateral ischemia $(P=.01)$.

Leaflet geometry during early systole ( 2 frames after end-diastole) in the three groups before and during 

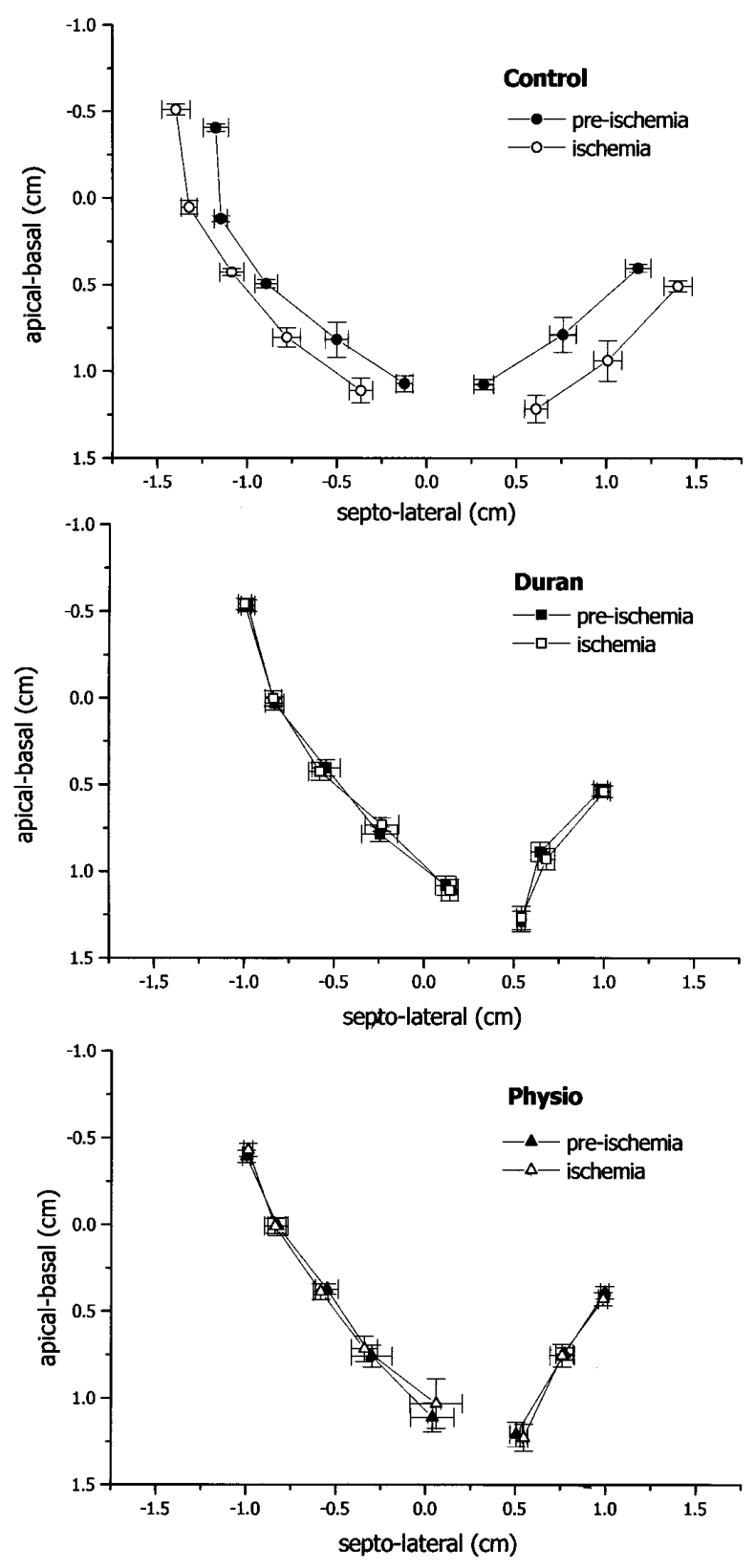

Fig 3. Leaflet shape (derived from the 3-dimensional coordinates of leaflet markers) during early systole ( 2 frames [33.4 $\mathrm{ms}$ ] after end-diastole) under baseline (solid symbols) and ischemic (open symbols) conditions for all three groups. At this time the valve is closed under all experimental conditions except ischemic control. Error bars indicate 1 standard error of the mean.

ischemia is graphically illustrated in Fig 3 . At this time the valve was closed under all experimental conditions except in the control group during ischemia. In the control group, both leaflets retained their concave geometry toward the atrium during ischemia. However, due to

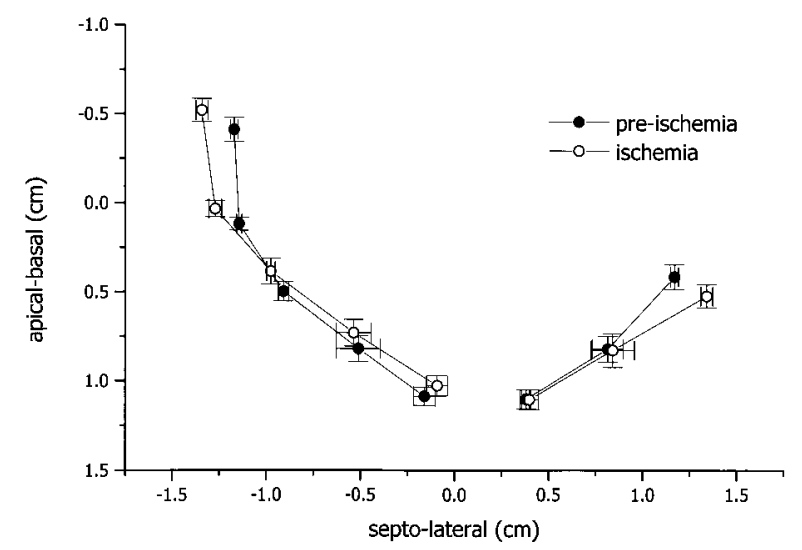

Fig 4. Leaflet shape, derived from the 3-dimensional coordinates of leaflet markers, at the time of valve closure in the control group before (closed circles) and during (open circles) acute posterolateral ischemia. The graphs represent leaflet shape at $16.7 \mathrm{~ms}$ and $83.5 \mathrm{~ms}$ after end-diastole for preischemic and ischemic valve closure, respectively. Error bars indicate 1 standard error of the mean.

increased separation of their annular hinge points, the leaflet edge markers were farther apart during early systole. Coaptation was delayed during ischemia, but the leaflet edge markers eventually reached the same final position to close the valve as they did before the ischemic insult (see Fig 4). In the two ring groups, leaflet shape was different as evidenced by lack of concavity of the posterior leaflet and decreased curvature of the anterior leaflet, but this geometry did not change during ischemia. No separation of the annular hinge points was noted in either ring group, and leaflet edge separation during early systole did not change with ischemia.

Mitral annular area and shape. An average increase of $19 \% \pm 7 \%$ in end-diastolic mitral annular area (6.74 $\pm 0.64 \mathrm{~cm}^{2}$ vs $\left.8.02 \pm 0.89 \mathrm{~cm}^{2}, P=.004\right)$ was observed in the control group during ischemia (maximum $=20 \%$ $\pm 7 \%$ one frame after end-diastole). At the time of valve closure, mitral annular area was still 13\% $\pm 9 \%$ larger during ischemia. As listed in Table III, mitral annular area was smaller than control size in the Duran and Physio groups but similar between the 2 ring types (Duran $5.10 \pm 0.68 \mathrm{~cm}^{2}$ vs Physio $4.78 \pm 0.43 \mathrm{~cm}^{2}, P$ > .2) and remained fixed during the cardiac cycle; more important, there was no significant change in mitral annular area between baseline and ischemic conditions, as depicted in Fig 2.

Changes in S-L and C-C dimensions are shown in Fig 5 and summarized in Table III. In the control group, a significant increase in S-L distance $(14 \% \pm 9 \%)$ was observed at end-diastole during ischemia, in contrast to a negligible change $(+1.6 \% \pm 3.6 \%)$ in the $\mathrm{C}-\mathrm{C}$ dis- 


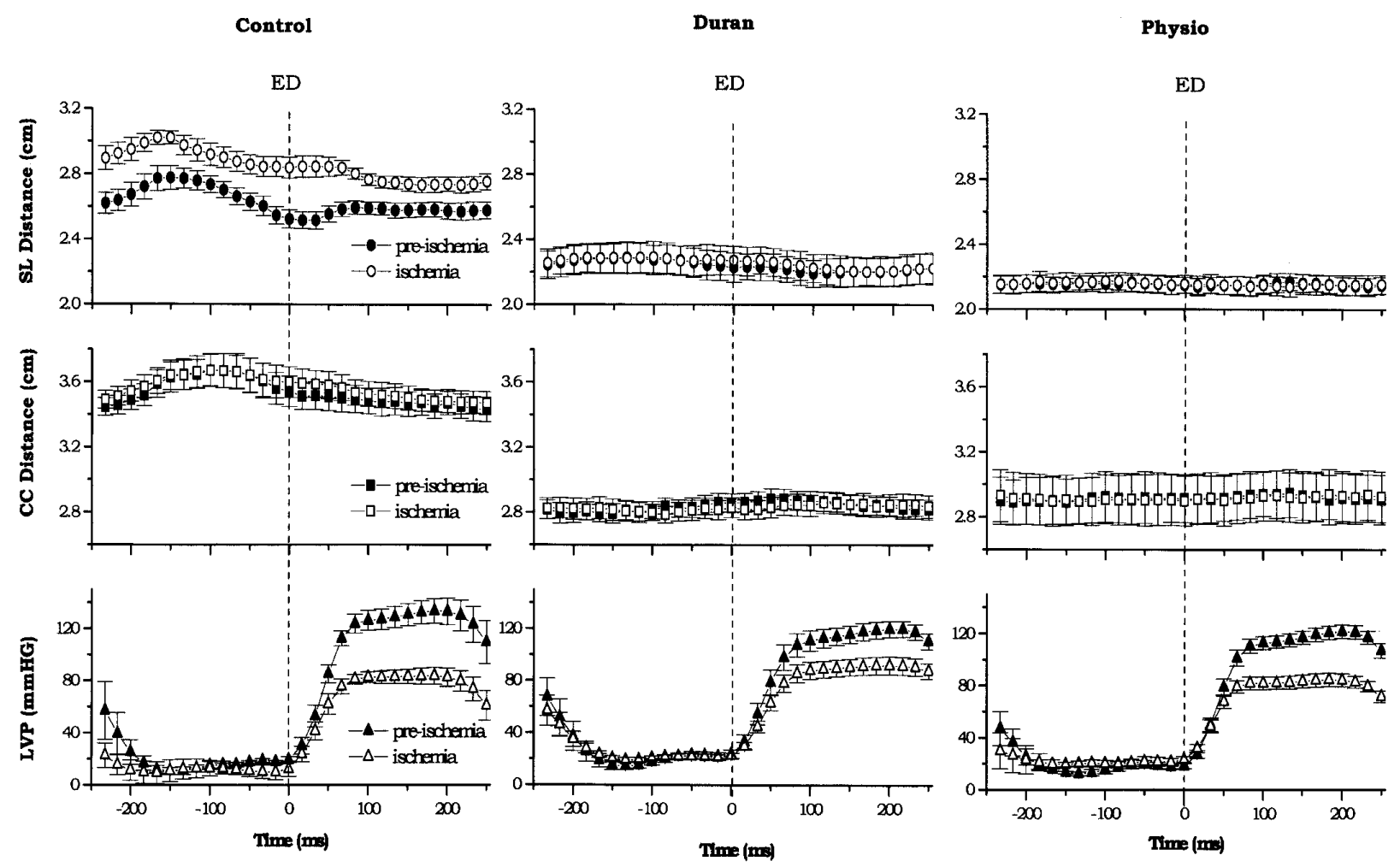

Fig 5. Septal-lateral $(S L)$ distance $(\mathrm{cm})$, commissure-commissure $(C C)$ dimension $(\mathrm{cm})$, and LV pressure $(L V P)$ $(\mathrm{mm} \mathrm{Hg})$ before (closed symbols) and during (open symbols) acute posterolateral LV ischemia. A 500-ms time frame centered at end-diastole (dashed lines) is shown for all three groups. Error bars indicate 1 standard error of the mean.

tance. These geometric changes led to an increase in the S-L/C-C ratio of the mitral anulus at end-diastole under ischemic conditions $(0.71 \pm 0.05$ vs $0.80 \pm 0.08$, $P=.02)$. Under both baseline and ischemic conditions, the S-L and C-C dimensions were quite dynamic throughout the cardiac cycle in the control group. In the Duran ring group, the S-L dimension varied little during the cardiac cycle, although a small increase was noted at end-diastole during ischemia $(2.23 \pm 0.23 \mathrm{~cm}$ vs $2.27 \pm 0.22 \mathrm{~cm}, P=.05)$. The $\mathrm{C}-\mathrm{C}$ dimension remained fixed throughout the cardiac cycle during ischemia. In the Physio ring group, even less variability in S-L and C-C dimensions was observed (ie, mitral annular size and shape were fixed during control and ischemia). As expected, both S-L and C-C dimensions in both ring groups were significantly smaller than those in the control group, during both baseline and ischemic conditions.

Papillary muscles. No significant change in the 3dimensional coordinates of the posterior and anterior papillary muscle tips from baseline was noted at enddiastole in any of the three groups during the acute ischemic insult.

\section{Discussion}

The pathophysiology of ischemic MR has been ascribed to pathologic perturbations in the 3-dimensional geometry of the left ventricle and the mitral subvalvular apparatus due to ischemia and infarction. Annular changes, ${ }^{10,17}$ systolic leaflet tethering, ${ }^{18,19}$ more spherical ventricular shape, ${ }^{20,21}$ and depressed systolic function ${ }^{22}$ have all been thought to contribute to this process. Mitral annuloplasty alone is believed to be effective in abolishing ischemic MR in some patients with normal valve morphology, yet the precise mechanism of how annular fixation prevents ischemic MR is not known, and satisfactory clinical results are not uniformly reproducible. Whether simple annular reduction or attendant changes in the 3-dimensional geometry of the subvalvular apparatus or both are responsible is speculative. This experiment demonstrated that delayed leaflet coaptation and MR during acute LV ischemia can be prevented by just reducing and fixing annular size.

Mitral leaflet coaptation and mitral annular area. During acute LV ischemia, leaflet coaptation was significantly delayed in the control group, as previously 
described,10 and this early systolic leaflet "loitering" was associated with MR. Annular dilatation was maximal during this period, and therefore the leaflets had to traverse more distance to reach coaptation. As the timing of the regurgitant jet could not be determined, no concrete cause-and-effect relationship between delayed leaflet coaptation and regurgitation was possible. A canine experiment showed that an isolated $25 \%$ increase in mitral annular circumference with an externally adjustable rigid mitral ring resulted in $3+\mathrm{MR},{ }^{23}$ which resolved when the ring was reduced to its original size. This increase in annular dimension would result in a greater increase in area than that observed in our study but illustrates that MR can result from annular dilatation alone. Rigid fixation with an oversized mitral ring was also observed to cause valve incompetence by other investigators in dogs, ${ }^{24}$ but mitral ring annuloplasty with either a flexible or semiflexible ring reduced annular size such that dilatation did not occur during ischemia. Similar mitral annular fixation in our study abolished both ischemic MR and delayed leaflet coaptation. Therefore, by bringing the leaflets closer together at end-diastole, annuloplasty may allow for timely systolic coaptation and nonregurgitant closure during ischemia. This notion is indirectly supported by the work of Bolling and associates, ${ }^{25}$ who observed that annuloplasty alone was effective in reducing MR in patients with idiopathic dilated cardiomyopathy, who generally had normal leaflet motion (Carpentier type I) before the operation. On the other hand, ischemic MR can persist in patients after annuloplasty because of apical tenting of the leaflets, which restricts closing during systole (Carpentier type IIIb leaflet motion). ${ }^{26}$ Thus more than one mechanism may be responsible for MR in chronically volume-overloaded dilated human hearts.

Mitral leaflet area has been reported to exceed the annular orifice by $52 \%$ in sheep, ${ }^{27}$ and this gross redundancy was believed to preclude MR from occurring due to annular dilatation alone. It is the combined height of both leaflets in the S-L axis, however, that is primarily responsible for valvular competence. As leaflet coaptation occurs apically to the annular plane and the leaflets are usually thought to be concave (to the ventricle) during closure, redundancy of the combined leaflet height may effectively be much less with respect to the S-L annular dimension. Therefore small changes in the S-L diameter, such as those observed with our model of acute LV ischemia, may perturb this relationship sufficiently to create incomplete mitral leaflet coaptation. Annuloplasty increases the ratio of mitral leaflet to annular area and thereby promotes coaptation primarily by reducing the S-L annular dimension.
Mitral annular shape. The alterations in annular dimensions in the control group during ischemia were characterized by a significant increase in the S-L diameter with little change in the $\mathrm{C}-\mathrm{C}$ axis, corresponding to the findings of others. ${ }^{28}$ These observations corresponded with a more circular shape of the anulus at end-diastole. Ring annuloplasty abolished these shape changes during the cardiac cycle and significantly reduced both the S-L and C-C dimensions. A smaller, fixed S-L diameter after ring annuloplasty would facilitate valve closure as it acts orthogonal to the leaflet coaptation zone. Therefore an important mechanism of ring annuloplasty may be reducing the S-L dimension, since this is the principal direction of annular enlargement during ischemia. ${ }^{8,10,28}$ This concept is corroborated by a recent study from our laboratory in which experimental manipulation that enlarged the $\mathrm{C}-\mathrm{C}$ axis (but not the $\mathrm{S}-\mathrm{L}$ axis) resulted in a $15 \%$ to $17 \%$ increase in mitral annular area that was not associated with any MR. ${ }^{29}$ Interestingly, the 1 animal that did have MR had an increase in the S-L diameter of greater than 2 SDs larger than the mean value, in addition to considerable

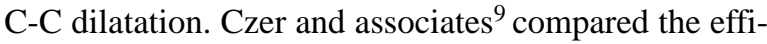
cacy of ring versus suture annuloplasty in patients undergoing coronary revascularization and mitral valve repair and found a greater degree of postoperative MR in the suture annuloplasty group; moreover, patients in the ring group had a greater reduction in S-L mitral diameter as measured echocardiographically. Since dilatation of the posterior anulus is primarily responsible for the augmented mitral annular S-L dimension, our findings suggest that simple posterior annuloplasty alone may possibly be sufficient to prevent ischemic MR

Papillary muscle geometry. No difference in papillary muscle tip position during ischemia was noted in the three groups at end-diastole compared with baseline. (Note that our previously mentioned very small change in end-diastolic posteromedial papillary muscle tip position ${ }^{10}$ in these same control animals was due to a timing difference in defining end-diastole [beginning of the R-wave upstroke in our 1998 report and the peak of the QRS signal now] and a technical error on our part in temporal registration. The data shown in this article for the papillary muscle tip positions were validated by three individuals working independently.) Since annuloplasty was not associated with end-diastolic papillary muscle displacement during ischemia, yet abolished MR and early systolic incomplete mitral leaflet coaptation, it is reasonable to conjecture that incomplete coaptation was primarily due to annular dilatation (which is maximal during this time period) and not due to leaflet tethering. Although acute MR 
resulting from leaflet tethering has been described in the $\operatorname{dog},{ }_{19}$ "functional" MR in that study was due to combined global LV ischemia and LV dilation. As neither end-diastolic volume nor papillary position changed with ischemia in our study, leaflet tethering is an unlikely mechanism for leaflet loitering and incomplete mitral leaflet coaptation during acute posterolateral LV ischemia in this experimental preparation.

\section{Study limitations}

First, it must be emphasized that previous implantation of an annuloplasty ring before the ischemic insult ("prevention" of ischemic MR as shown here) is clearly not analogous to the clinical situation, in which ischemia or an infarction occurs and then is treated surgically with placement of a ring. This is a major and important limitation of this model. Second, these findings can be interpreted only in the setting of acute LV ischemia in a normal sheep heart and cannot be extrapolated directly to chronic ischemic MR where LV dilatation, subvalvular geometric perturbations induced by previous infarction and ischemia, and LV remodeling may play a more predominant role. This point must be emphasized because chronic MR in a clinical situation may alter annular geometry and function in ways not reflected in our acute experimental model. Thus, although our ovine preparation provides valuable data regarding mechanisms and treatment of acute ischemic MR, caution must be used in extrapolating these data in the human setting of chronic MR. Third, it was not possible in this study to determine the exact timing of the MR; therefore, the MR created by circumflex occlusion in this sheep model could have occurred in late systole and not be related to the delayed coaptation and incomplete mitral leaflet coaptation seen in early systole. This is unlikely, however, as no MR was observed in the ring groups when delayed leaflet closure was also prevented. Further studies are needed to better characterize the timing of ischemic MR in this experimental preparation.

As the leaflet markers were placed only on the central meridian of each leaflet, no data are available pertaining to leaflet motion and coaptation near the commissures or involving the anterolateral or posteromedial leaflet scallops, where delayed coaptation may also be present. We are planning future experiments with a denser array of leaflet edge markers to address this question. The myocardial marker method provides reproducible determination of 3-dimensional marker positions with sub-millimeter spatial resolution every $16.7 \mathrm{~ms}$, but it requires suturing small metal markers to intracardiac structures. It is unlikely that the markers interfered with mitral leaflet motion because they are very small (aggregate mass $=20 \pm 6 \mathrm{mg}$ ); even when we grossly overloaded the anterior leaflet with a larger number of excessively heavy markers (total mass $=184$ $\mathrm{mg}$ ) in other animals, the peak anterior leaflet opening velocity by epicardial pulse wave Doppler echocardiography was $0.47 \pm 0.05 \mathrm{~m} / \mathrm{s}$ compared with $0.45 \pm 0.06$ $\mathrm{m} / \mathrm{s}$ for leaflets without any markers implanted. The peak E-wave velocities ranged from 0.55 to $0.60 \mathrm{~m} / \mathrm{s}$ (unpublished data).

Finally, this animal model has other intrinsic limitations; sheep have a less defined posterior anulus than human beings and more atrial tissue above and below the line of leaflet insertion. ${ }^{30}$ The amount of atrial fibers in the human anulus, however, is quite variable. ${ }^{31}$ Nonetheless, extrapolation of these results to clinical situations must be done with caution. On the other hand, the ovine model is more relevant to human pathophysiology than the canine model, because the dog heart has multiple pre-formed coronary collaterals. ${ }^{32}$ Finally, to get close to the real clinical problem, this type of investigation needs to be conducted in long-term animal preparations after myocardial infarction with subsequent ischemic MR, LV remodeling, and chronic volume overload.

We appreciate the superb technical assistance provided by Mary K. Zasio, BA, Carol W. Mead, BA, and Erin K. Schultz, BS.

\section{REFERENCES}

1. Edmunds LH Jr. Ischemic mitral regurgitation. In: Edmunds LH, editor. Cardiac surgery in the adult. 1st ed. New York: McGrawHill; 1997. p. 657-76.

2. Czer LSC, Gray RI, DeRobertis MA, Bateman TM, Stewart ME, Chaux A, et al. Mitral valve replacement: impact of coronary artery disease and determinants of prognosis after revascularization. Circulation 1984;70(Suppl):I-198-207.

3. Connolly MW, Gelbfish JS, Jacobowitz IJ, Rose DM, Mendelsohn A, Cappabianca PM. Surgical results for mitral regurgitation from coronary artery disease. J Thorac Cardiovasc Surg 1986;91: 379-88.

4. Replogle RL, Campbell CD. Surgery for mitral regurgitation associated with ischemic heart disease. Circulation 1989;79 (Suppl):I-122-5.

5. Oury JH, Cleveland JC, Duran CG, Angell WW. Ischemic mitral valve disease: classification and systemic approach to management. J Card Surg 1994;9(Suppl):262-73.

6. Dion R. Ischemic mitral regurgitation: When and how should it be corrected? J Heart Dis 1993;2:536-43.

7. Carpentier A. Cardiac valve surgery-the "French correction." J Thorac Cardiovasc Surg 1983;86;323-37.

8. Kay GL, Kay JH, Zubiate P, Yokoyama T, Mendez M. Mitral valve repair for mitral regurgitation secondary to coronary disease. Circulation 1986;74(Suppl):I-88-98.

9. Czer LSC, Maurer G, Trento A, DeRobertis M, Nessim S, Blanche $\mathrm{C}$, et al. Comparative efficacy of ring and suture annuloplasty for 
ischemic mitral regurgitation. Circulation 1992;86(Suppl):II-4652.

10. Glasson JR, Komeda M, Daughters GT, Bolger AF, Karlsson MO, Foppiano LE, et al. Early systolic mitral leaflet "loitering" during acute ischemic mitral regurgitation. J Thorac Cardiovasc Surg 1998;116:193-205.

11. Ingels NB Jr, Daughters GT, Stinson EB, Alderman EL. Measurement of midwall myocardial dynamics in intact man by radiography of surgically implanted markers. Circulation 1975; 52:859-67.

12. Glasson JR, Komeda M, Daughters GT, Foppiano LE, Bolger AF, Tye TL, et al. Most ovine mitral annular three-dimensional size reduction occurs before ventricular systole and is abolished with ventricular pacing. Circulation 1997;96(Suppl):II-115-23.

13. Schipke JD, Harasawa Y, Suigura S, Alexander J, Burkhoff D. Effect of a bradycardic agent on the isolated blood-perfused canine heart. Cardiovasc Drugs Ther 1991;5:481-8.

14. Niczyporuk MA, Miller DC. Automatic tracking and digitization of multiple radiopaque myocardial markers. Comput Biomed Res 1991;24:129-42.

15. Moon MR, DeAnda A, Daughters GT, Ingels NB, Miller DC. Experimental evaluation of different chordal preservation methods during mitral valve replacement. Ann Thorac Surg 1994;58: 931-44.

16. Moon MR, Castro LJ, Derby GC, Niczyporuk MA, Daughters GT, Ingels NB Jr, et al. Calculation of biventricular volume: myocardial marker vs. sonomicrometric shell subtraction technique [abstract]. Circulation 1992;86(Suppl):I-553.

17. Boltwood CM, Tei C, Wong M, Shah PM. Quantitative echocardiography of the mitral complex in dilated cardiomyopathy: mechanism of functional mitral regurgitation. Circulation 1983; 68:498-508.

18. He S, Fontaine AA, Schwammenthal E, Yoganathan AP, Levine RA. Integrated mechanism for functional mitral regurgitation. Circulation 1997;96:1826-34.

19. Otsuji Y, Handschummacher MD, Schwammenthal E, Jiang L, Song JK, Guerrero JL, et al. Insights from three-dimensional echocardiography into the mechanism of functional mitral regurgitation. Circulation 1997:96:1999-2008.

20. Kono T, Sabbah HN, Rosman H, Alam M, Jafri S, Goldstein S. Left ventricular shape is the primary determinant of functional mitral regurgitation in heart failure. J Am Coll Cardiol 1992;7: 1594-8.

21. Sabbah HN, Kono T, Stein PD, Mancini GB, Goldstein S. Left ventricular shape changes during the course of evolving heart failure. Am J Physiol 1992;263:H266-70.

22. Kaul S, Spotnitz WD, Glasheen WP, Touchstone DA. Mechanism of ischemic mitral regurgitation. Circulation 1991;84:2167-80

23. Ahmandi A, Spillner G, Johannesson T. Hemodynamic changes following experimental production and correction of acute regurgitation with an adjustable ring prosthesis. Thorac Cardiovasc Surg 1988;36:313-9.

24. Hawe A, Tsakiris AG, McGoon DC. Experimental production of chronic graded mitral stenosis. J Thorac Cardiovasc Surg 1970; 60:559-64.

25. Bolling SF, Pagani FD, Deeb GM, Bach DS. Intermediate-term outcome of mitral reconstruction in cardiomyopathy. $\mathrm{J}$ Thorac Cardiovasc Surg 1998;115:381-8.

26. Liel-Cohen N, Otsuji Y, Vlahakes GJ, Akins CW, Levine RA. Functional ischemic mitral regurgitation can persist despite ring annuloplasty: mechanistic insights [abstract]. Circulation 1997; 96(Suppl):I-540.

27. Gorman JH, Jackson BM, Gorman RC, Kelley ST, Gikakis N, Edmunds LH Jr. Papillary muscle discoordination rather than increased annular area facilitates mitral regurgitation after acute posterior myocardial infarction. Circulation 1997;96(Suppl):II124-7.

28. Gorman JH, Gorman RC, Jackson BM, Hiramatsu Y, Gikakis N, Kelley ST, et al. Distortions of the mitral valve in acute ischemic mitral regurgitation. Ann Thorac Surg 1997;64:1026-31.

29. Green GR, Dagum P, Glasson JR, Daughters GT, Foppiano LE, Berry GJ, et al. Mitral annular dilatation and papillary muscle dislocation without mitral regurgitation in sheep [abstract]. Circulation 1998;98(Suppl):I-475.

30. Walmsley R. Anatomy of human mitral valve in adult cadaver and comparative anatomy of the valve. Br Heart J 1978;40:351-66.

31. Angelini A, Ho SY, Davies MJ, Becker A. A histological study of the atrioventricular junction in hearts with normal and prolapsed leaflets of the mitral valve. Br Heart J 1988;59:712-6.

32. Blair E. Anatomy of the ventricular coronary arteries in the dog. Circ Res 1961;9:333-41.

\section{Availability of Journal back issues}

As a service to our subscribers, copies of back issues of The Journal of Thoracic and Cardiovascular Surgery for the preceding 5 years are maintained and are available for purchase from Mosby until inventory is depleted. The following quantity discounts are available: $25 \%$ off on quantities of 12 to 23, and one third off on quantities of 24 or more. Please write to Mosby, Inc, Subscription Services, 11830 Westline Industrial Drive, St Louis, MO 63146-3318, or call 800-453-4351 or 314-453-4351 for information on availability of particular issues and prices. If unavailable from the publisher, photocopies of complete issues may be purchased from Bell \& Howell Information and Learning, $300 \mathrm{~N}$ Zeeb Rd, Ann Arbor, MI 48106-1346; 734-761-4700 or 800-521-0600. 